\title{
Perancangan Program Aplikasi Penjualan Suku Cadang Mobil Dengan Menggunakan Bahasa Pemrograman Ms. Visual Basic 6.0 Pada PD.Kencana Baru Bandar Lampung
}

\author{
Marzuki \\ Program Studi Teknik Informatika \\ Fakultas Ilmu Komputer \\ Universitas Bandar Lampung \\ Jln. Z.A. Pagar Alam No.26 Labuhan Ratu Bandar Lampung 35142 \\ Telp. (0721) 701463, (0721) 701979 Fax. (0721) 701467 Web. www.ubl.ac.id
}

\begin{abstract}
Abstrak
Pada masa kini, perkembangan dan kemajuan teknologi informasi terus berjalan. Untuk dapat bersaing sesuai dengan perkembangan zaman, PD.Kencana Baru Bandar Lampung diharapkan meninggalkan cara manual dalam mencatat transaksi penjualan suku cadang, karena akan mengurangi efektifitas kerja sehingga hasilnya kurang dirasakan optimal. Pembuatan skripsi ini bertujuan untuk merancang program aplikasi penjualan Suku cadang yang dapat membantu dalam transaksi penjualan suku cadang pada PD.Kencana Baru Bandar Lampung. Skripsi ini akan menggambarkan serta menjelaskan rancangan program aplikasi penjualan suku cadang pada PD.Kencana Baru. Dalam merancang program, peneliti menggunakan tahapan-tahapan perancangan program yang dijelaskan pada bagian keempat dari skripsi ini Kata kunci : aplikasi penjualan Suku cadang
\end{abstract}

\section{PENDAHULUAN}

Saat ini, tidak sedikit perusahaan yang masih menggunakan sistem manual dalam pengolahan data transaksi, sampai pembuatan laporan kepada pihak manajemennya. Ini dikarenakan mereka kurang menyadari arti pentingnya informasi bagi perusahaannya. Mereka berfikir walaupun tanpa sistem informasi terkomputerisasi, usahanya masih dapat berlangsung. Namun dalam pengolahan data transaksinya, sering terjadi kesalahan pemasukan data yang disebabkan oleh faktor manusia (human error), padahal laporan yang akan dibuat bergantung dari hasil pemasukan data tersebut. PD. Kencana Baru terletak di Jl. Gatot Subroto No.87.A Garuntang Bandar Lampung adalah salah satu perusahaan yang bergerak di bidang penyedia jasa perbaikan mobil di Bandar Lampung, disamping itu PD. Kencana Baru juga menjual barang-barang suku cadang mobil. Dalam pengolahan data penjualannya PD. Kencana Baru, menggunakan sistem semikomputerisasi, yang berarti dalam pencatatan data transaksi masih digunakan cara manual, komputer hanya digunakan untuk membuat laporan kepada pihak manajemen. Hal ini membuat pengolahan data kurang efektif untuk mendukung keputusan manajemen. Karena inilah, maka peneliti ingin membantu merancang sebuah program aplikasi tentang Penjualan Suku Cadang Mobil pada PD.Kencana Baru di Bandar Lampung dengan menggunakan bahasa Pemrograman Visual Basic 6.0 sebagai salah satu bahan skripsi peneliti yang berjudul : "Perancangan Program Aplikasi Penjualan Suku Cadang Mobil Dengan Menggunakan Bahasa Pemrograman Ms. Visual Basic 6.0 Pada PD.Kencana Baru Bandar Lampung “.

\subsection{IDENTIFIKASI DAN PERUMUSAN MASALAH}

\subsubsection{Identifikasi Masalah}

Sistem yang berjalan dalam penjualan suku cadang mobil pada PD.Kencana Baru selama ini ternyata masih banyak menimbulkan masalahmasalah. Berikut ini disajikan masalah-masalah yang sering timbul :

1. Kesalahan pencatatan transaksi.

2. Laporan yang kurang akurat.

3. Sulitnya melakukan pencarian data transaksi. Dari permasalahan-permasalahan tersebut, peneliti mengidentifikasi hal-hal penyebab timbulnya masalah-masalah tersebut yaitu :

1. Pencatatan data transaksi penjualan yang masih menggunakan cara manual ternyata 
menimbulkan kesalahan-kesalahan umum yang terjadi akibat faktor manusia (human error), seperti kesalahan pencatatan harga.

2. Pembuatan laporan yang didasarkan dari pemasukan data yang salah menghasilkan laporan penjualan yang tidak akurat kepada pihak manajemen.

3. Penyimpanan data transaksi dalam bentuk arsip berupa kertas-kertas dirasakan tidak efektif untuk pencarian kembali. Selain itu kertas-kertas juga menyita tempat penyimpanan dan mudah rusak.

\subsubsection{Perumusan Masalah}

Berdasarkan identifikasi masalah tersebut, maka peneliti merumuskan masalah bagaimanakah Perancangan Program Aplikasi Penjualan Suku Cadang Mobil Dengan Menggunakan Bahasa Pemrograman Ms. Visual Basic 6.0 Pada PD.Kencana Baru Bandar Lampung yang efektif dan efisien?

\subsection{BATASAN MASALAH}

1. Adapun batasan masalah dalam penelitian proposal ini adalah :

Perancangan program ini hanya sebatas mengenai penjualan suku cadang mobil yang mencakup transaksi penjualan tunai, dan pembuatan laporan penjualan suku cadang mobil.

2. Bahasa pemrograman yang digunakan untuk membuat sistem suku cadang mobil pada PD.Kencana Baru adalah Visual Basic 6.0.

\subsection{MANFAAT DAN TUJUAN}

\subsubsection{MANFAAT}

Program aplikasi yang dibuat dengan menggunakan bahasa pemrograman Visual Basic 6.0 diharapkan dapat memberikan manfaat, diantaranya :

1. Mempermudah dalam Penginputan data transaksi penjualan, penghitungan pembayaran serta pencarian kembali data transaksi penjualan.

2. Mempermudah dalam pembuatan laporan penjualan suku cadang mobil yang akan diberikan kepada Pimpinan PD.Kencana baru.

\subsubsection{TUJUAN}

Tujuan peneliti dalam membuat penelitian ilmiah ini adalah :

1. Merancang aplikasi suku cadang mobil dengan menggunakan Visuak basic 6.0

\section{LANDASAN TEORI}

\subsection{Model SoftwareEngineering}

Krisis software tidak dapat hilang dalam satu satu malam, di mana tidak ada suatu pendekatan yang baik dalam mengatasi krisis software, namun gabungan dari metode untuk semua fase dalam pengembangan siftware seperti peralatan yang lebih baik untuk mengautomatisasi metodemetode ini, tehnik yang lebih baik untuk mengontrol kualitas, dan filosofi untuk koordinasi kontrol, serta manajemen dipelajari dalam suatu disiplin ilmu yang kita sebut software engineering.

Menurut Fritz Badar, software engineering adalah disiplin ilmu yang menerapkan prinsip-prinsip engineering agar mendapatkan software yang ekonomis yang dapat dipercaya dan bekerja lebih efisien pada mesin yang sebenarnya.

Software engineering terdiri dari 3 elemen kunci, yaitu :

1. Metode / Methods

2. Peralatan / tools

3. Prosedur / Procedures

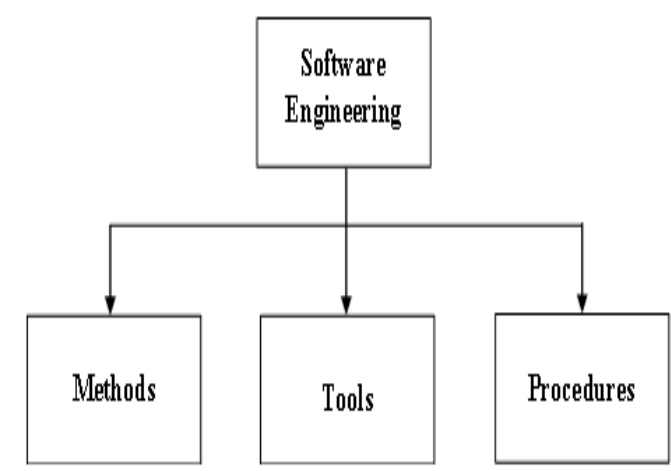

\section{Gambar 2.1 Three components of Software} Engineering

Dengan ketiga kunci itu manajer dapat mengontrol proses pengembangan software dan memberikan praktisi dasar yang baik untuk pembentukan software berkualitas tinggi.

1. Metode Software Enginnering

Metode software engineering memberikan tehnik-tehnik bagaimana membentuk software. Metode ini terdiri dari serangkaian tugas :

a. Perencanaan \& estimasi proyek

b. Analisis kebutuhan sistem dan software

c. Desain struktur data

d. Arsitektur program dan prosedur algoritma

e. Coding

f. Testing dan pemeliharaan

2. Peralatan Software Engineering 
Peralatan software engineering memberikan dukungan atau semiautomasi untuk metode. Contohnya

a. CASE (Case Aided Software Engineering), yaitu suatu software yang menggabungkan software, hardware, dan database software engineering untuk menghasilkan suatu lingkungan software engineering.

b. Database Software Engineering, adalah sebuah struktur data yang berisi informasi penting tentang analisis, desain, kode dan testing.

c. Analogi dengan CASE pada hardware adalah : CAD, CAM, CAE

3. Prosedur Software Engineering Terdiri dari:
a. urut-urutan di mana metode tersebut diterapkan
b. dokumen
c. laporan-laporan
d. formulir-formulir yang diperlukan
e. mengontrol kualitas software
f. mengkoordinasi perubahan yang terjadi pada software
Dalam penguasaan atas model software engineering atau software engineering paradigm, dikenal ada 3 metode yang luas dipergunakan, yaitu :

\section{Model Siklus Hidup Klasik}

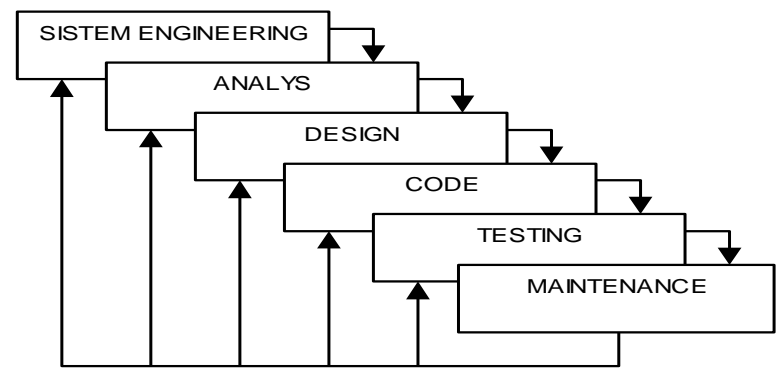

Gambar 2.2 Model siklus hidup klasik

Keterangan :

a. System Engineering

Karena software merupakan bagian terbesar dari sistem, maka pekerjaan dimulai dengan cara menerapkan kebutuhan semua elemen sistem dan mengalokasikan sebagian kebutuhan tersebut ke software. Pandangan terhadap sistem adalah penting, terutama pada saat software harus berhubungan dengan elemen lain, seperti :

\section{- Hardware}

\section{- Software \\ - Database}

b. Analisis kebutuhan software

Suatu proses pengumpulan kebutuhan software untuk mengerti sifat-sifat program yang dibentuk software engineering, atau analis harus mengerti fungsi software yang diinginkan, performance dan interface terhadap elemen lainnya. Hasil dari analisis ini didokumentasikan dan direview / dibahas / ditinjau bersama-sama customer.

c. Design

Desain software sesungguhnya adalah proses multi step (proses yang terdiri dari banyak langkah) yang memfokuskan pada 3 atribut program yang berbeda, yaitu :

- Struktur data

- Arsitektur software

- Rincian prosedur

Proses desain menterjemahkan kebutuhan ke dalam representasi software yang dapat diukur kualitasnya sebelum mulai coding. Hasil dari desain ini didokumentasikan dan menjadi bagian dari konfigurasi software.

d. Coding

Desain harus diterjemahkan ke dalam bentuk yang dapat dibaca oleh mesin.

e. Testing

Segera sesudah objek program dihasilkan, pengetesan program dimulai. Proses testing difokuskan pada logika internal software. Jaminan bahwa semua pernyataan atau statements sudah dites dan lingkungan external menjamin bahwa definisi input akan menghasilkan output yang diinginkan.

f. Maintenance

Software yang sudah dikirim ke customer data berubah karena

- Software mengalami error

- Software harus diadaptasi untuk menyesuaikan dengan lingkungan external, misalnya adanya sistem operasi baru atau peripheral baru.

- Software yang lebih disempurnakan karena adanya permintaan dari customer. 
Masalah yang dihadapi dari model siklus hidup klasik adalah :

1. Proyek yang sebenarnya jarang mengikuti aliran sequential yang ditawarkan model ini. Iterasi (Pengulangan) selalu terjadi dan menimbulkan masalah pda aplikasi yang dibentuk oleh model ini.

2. Seringkali pada awalnya customer sulit menentukan semua kebutuhan secara explisit (jelas).

3. Customer harus sabar karena versi program yang jalan tidak akan tersedia sampai proyek software selesai dalam waktu yang lama.

\section{Model Prototype}

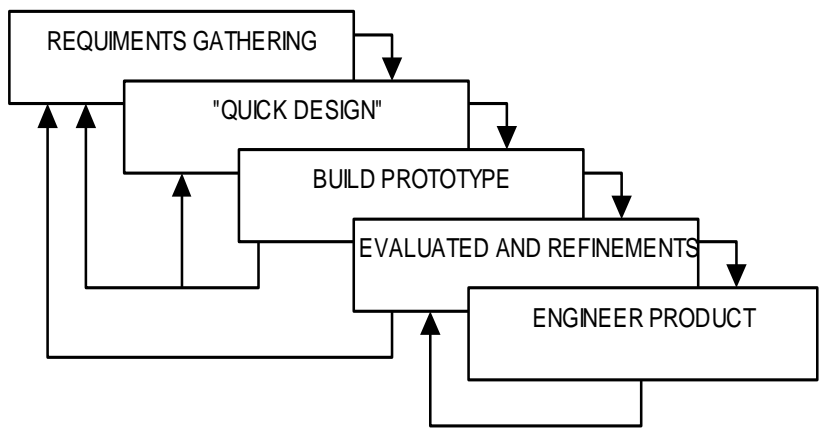

Gambar 2.3 Model prototype

Keterangan :

Seringkali seorang customer sulit menentukan input yang lebih terinci, proses yang diinginkan dan output yang diharapkan. Tentu saja ini menyebabkan developer tidak yakin dengan efisiensi alogoritma yang dibuatnya, sulit menyesuaikan sistem operasi, serta interaksi manusia dan mesin yang harus diambil. Dalam hal seperti ini, pendekatan prototype untuk software engineering merupakan langkah yang terbaik. Prototype sebenarnya adalah suatu proses yang memungkinkan developer membuat sebuah model software.Ada 2 bentuk dari model ini, yaitu :

a. Paper Prototype

Menggambarkan interaksi manusia dan mesin dalam sebuah bentuk yang memungkinkan user mengerti bagaimana interaksi itu terjadi.

b. Working Prototype

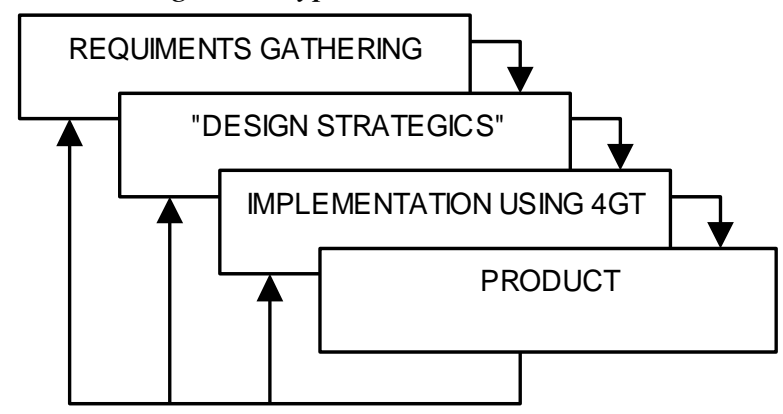

Adalah prototype yang mengimplementasikan beberapa bagian dari fungsi software yang diinginkan seperti pada pendekatan pengembangan software. Model ini dimulai dengan :

- Pengumpulan kebutuhan developer dan customer

- Menentukan semua tujuan software

- Mengidentifikasi kebutuhan-kebutuhan yang diketahui

Hasil dari pengumpulan kebutuhan diteruskan pada Quick Design. Quick Design ini memfokuskan pada representasi aspek-aspek software yang dapat dilihat oleh user, misalnya format input dan output, selanjutanya dari desain cepat diteruskan pada pembentukan prototype (langkah ke 3). Prototype ini dievaluasi oleh customer / user dan digunakan untuk memperbaiki kebutuhan-kebutuhan software. Proses iterasi terjadi agar prototype yang dihasilkan memenuhi kebutuhan customer, juga pada saat yang sama developer mengerti lebih baik tentang apa yang harus dikerjakan.Masalah yang dihadapi oleh model Prototype ini adalah :

Customer hanya melihat pada apa yang dihasilkan oleh software, tidak peduli pada hal-hal yang berhubungan dengan kualitas software dan pemeliharaan jangka panjang. Developer seringkali menyetujui apa yang diterangkan oleh customer agar prototype dapat dihasilkan dengan cepat. Akibatnya timbul pemilihan sistem operasi / bahasa pemrograman yang tidak tepat.

\section{Model tehnik generasi ke 4 / 4GT}

Istilah Fourth Generation Technique (4GT) meliputi seperangkat peralatan software yang memungkinkan seorang developer software menerapkan beberapa karakteristik software pada tingkat yang tinggi, yang kemudian menghasilkan source code dan object code secara otomatis sesuai dengan spesifikasi yang ditentukan developer. Saat ini peralatan / tools 4GT adalah bahasa non prosedur untuk :

a. DataBase Query

b. Pembentukan laporan ( Report Generation )

c. Manipulasi data

d. Definisi dan interaksi layar (screen)

e. Pembentukan object dan source (Object and source generation ) 
f. Kemampuan grafik yang tinggi, dan

g. Kemampuan spreadsheet

Keterangan gambar :

Model 4GT untuk software engineering dimulai dengan rangkaian pengumpulan kebutuhan. Idealnya, seorang customer menjelaskan kebutuhan-kebutuhan yang selanjutnay diterjemahkan ke dalam prototype. Tetapi ini tidak dapat dilakukan karena customer tidak yakin dengan apa yang diperlukan, tidak jelas dalam menetapkan fakta-fakta yang diketahui dan tidak dapat menentukan informasi yang diinginkan oleh peralatan 4GT.Untuk aplikasi kecil adalah mungkin bergerak langsung dari langkah pengumpulan kebutuhan ke implementasi yang menggunakan bahasa non prosedur fourth generation (generasi ke 4). Tetapi untuk proyek besar, pengembangan strategi desain sistem tetap diperlukan, sekalipun kita menggunakan 4GL. Penggunaan 4GT tanpa desain untuk proyek besar akan menyebabkan masalah yang sama yang ditemui dalam pengembangan software yang menggunakan pendekatan konvensional.Implementasi yang menggunakan 4GL memungkinkan developer software menjelaskan hasil yang diinginkan yang kemudian diterjemahkan ke dalam bentuk source code dan object code secara otomatis.

Langkah yang terakhir adalah mengubah implementasi 4GT ke dalam sebuah product. Selanjutnya developer harus melakukan pengetesan, pengembangan dokumentasi dan pelaksanaan semua aktifitas lainnya yang diwujudkan dalam model software engineering.

Masalah yang dihadapi dalam model 4GT adalah adanya sebagian orang yang beranggapan bahwa :

a. peralatan 4GT tidak semudah penggunaan bahasa pemrograman,

b. source code yang dihasilkan oleh peralatan ini tidak efisien,

c. pemeliharaan sistem software besar yang dikembangkan dengan 4GT masih merupakan tanda tanya.

\section{Model Kombinasi}

\section{Gambar 2.5 model kombinasi}

Keterangan :

Model ini menggabungkan keuntungankeuntungan dari beberapa model sebelumnya. Seperti pada model sebelumnya, model kombinasi ini dimulai dengan langkah pengumpulan kebutuhan. Pendekatan yang dapat diambil adalah pendekatan siklus hidup klasik (Analisis sistem

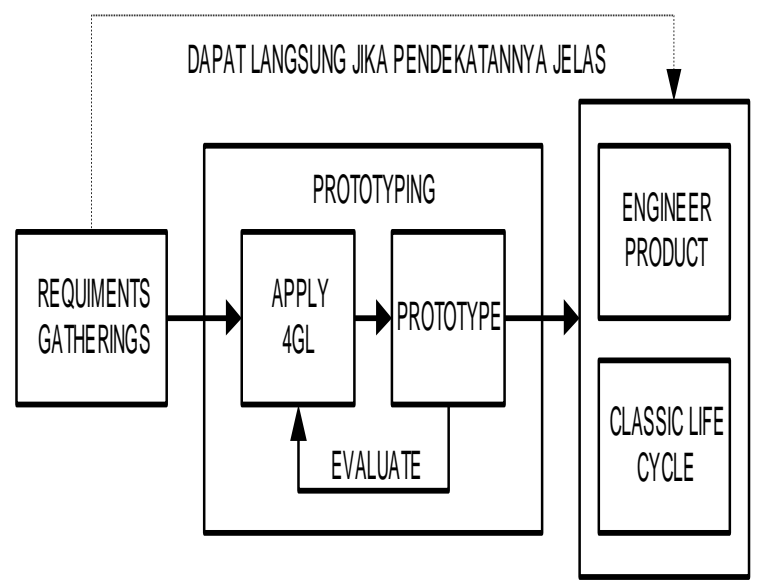

dan analisis kebutuhan software) atau dapat juga menggunakan pendekatan seperti prototyping jika definisi masalahnya tidak terlalu formal. Jika kebutuhan untuk fungsi dan performance software diketahui dan dimengerti, pendekatan yang dianjurkan adalah model siklus hidup klasik. Sebaliknya, jika aplikasi software menuntut interaksi yang sering antara manusia dan mesin, membutuhkan algoritma yang tidak dapat dibuktikan, atau membutuhkan tehnik output / kontrol, maka pendekatan yang dianjurkan adalah model prototyping.

\section{PERANCANGAN SISTEM}

Peneliti menyarankan spesifikasi yang dibutuhkan komputer Single-user antara lain :

1. Perangkat Keras (Hardware) yang di butuhkan yaitu :

- Intel Pentium III $800 \mathrm{MHz}$

- 128 MB RAM

- Kapasitas harddisk kosong minimal 10 GB

- CD-ROM drive

- Satu buah Printer inkjet

- UPS (Uninterruptible Power Supply) 220VA

- Monitor dengan resolusi VGA ukuran 14" atau lebih

- Mouse dan keyboard

2. Perangkat Lunak (Software) yang di butuhkan yaitu :

- Microsoft Windows 98/2000/XP (operating system)

- Microsoft Access 2000 (database)

- Microsoft Visual Basic 6.0

\subsection{METODOLOGI ANALISIS}


Dalam laporan penelitian ilmiah, peneliti menganalisa data-data yang diperoleh dengan menggunakan metode analisis:

1. Functional Decomposition Methodelogies Metodologi ini menekankan pada pemecahan masalah dari sitem ke sub-sub sistem yang lebih kecil sehingga akan lebih mudah untuk dipahami. Dalam skripsi ini, peneliti menggunakan beberapa Functional Decomposition Methodologies, yaitu :

- Diagram arus data (data flow diagram) atau DFD

- ERD (Entity Relationship Diagram)

- Kamus Data (Data Dictionary)

- Normalisasi

- Flow Of Document ( Bagan Alir Dokumen )

\subsubsection{DFD}

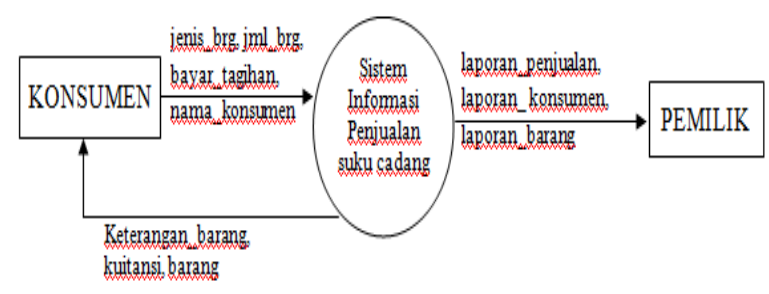

Gambar 3.2 Context Diagram Sistem Informasi Penjualan Suku Cadang pada PD. Kencana Baru

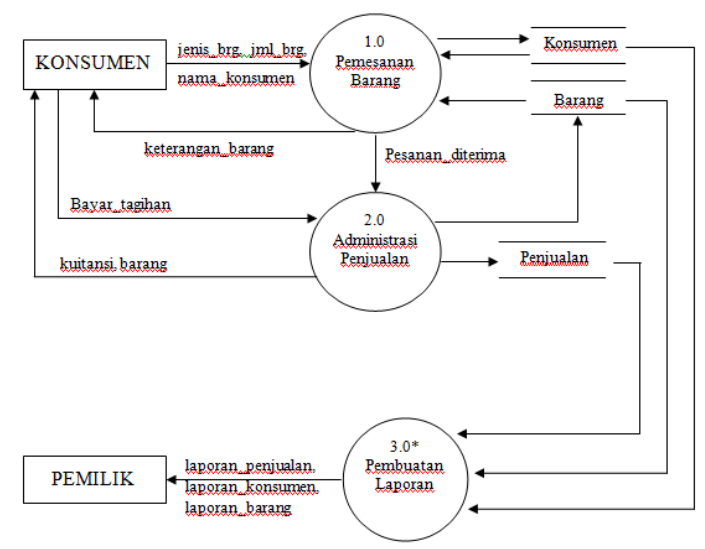

Gambar 3.3 Diagram Zero Sistem Informasi Penjualan Suku Cadang vada PD. Kencana Baru

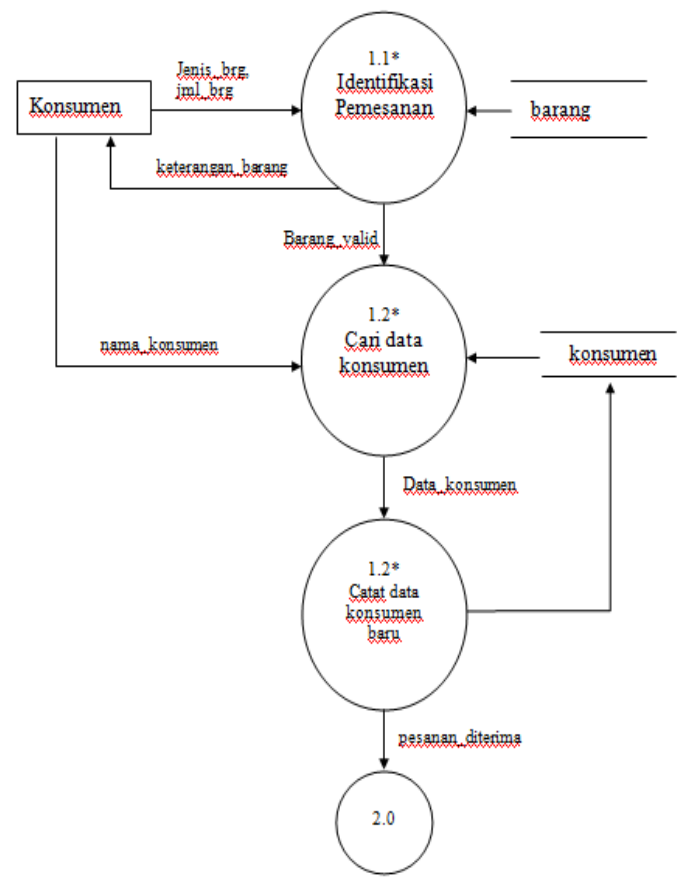

Gambar 3.4. Diagram Rinci Proses 1.0 Pemesanan Barang.

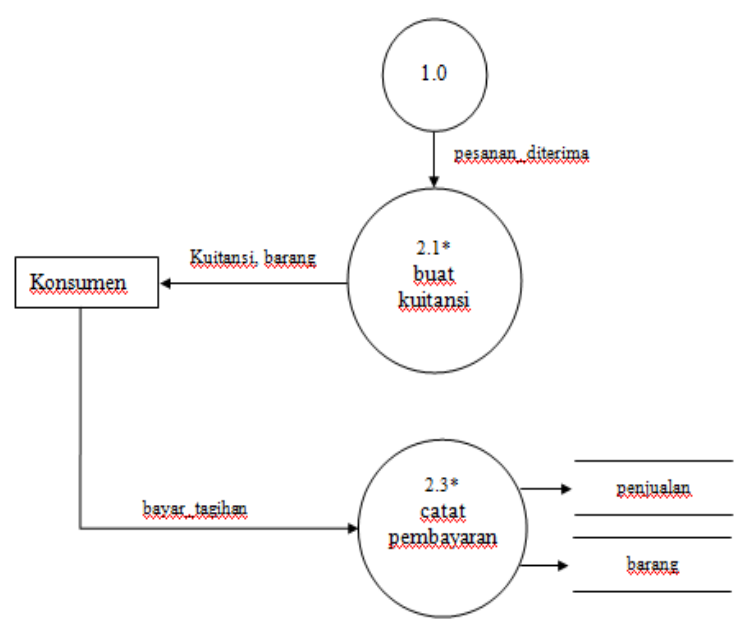

Gambar 3.5 Diagram Rinci Proses 2.0 Administrasi Penjualan 


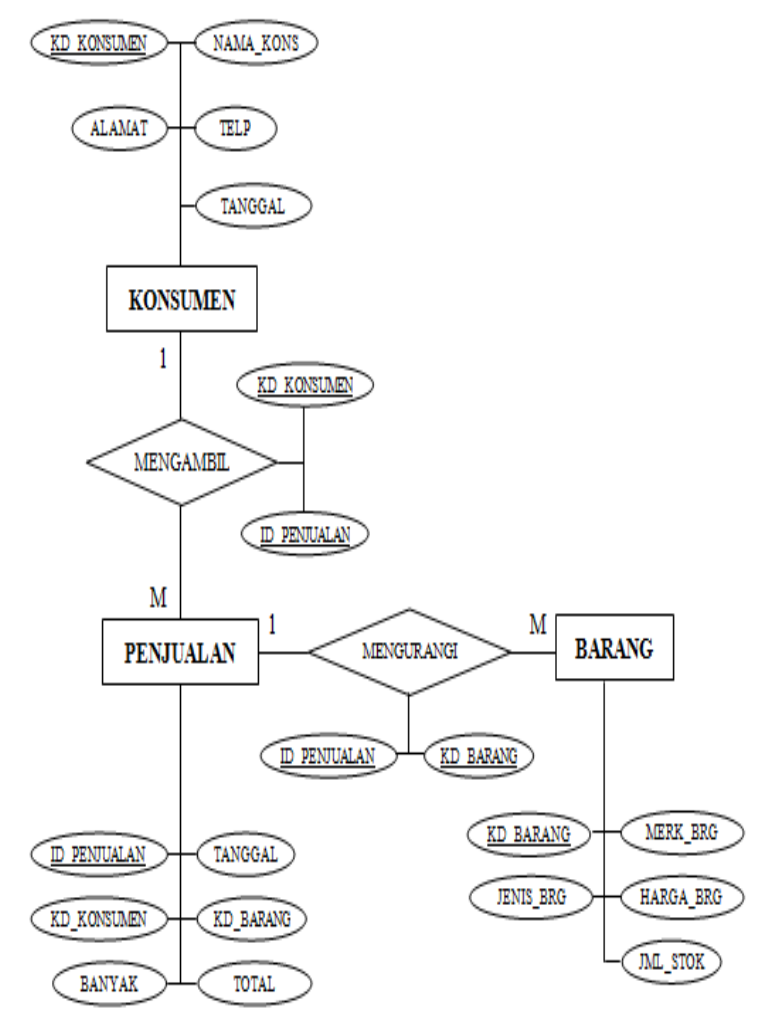

Gambar 3.6 Entity Relationship Diagram (ERD)

\subsubsection{Flow of document}

3.6 Diagram Alir. Dokumen (Flow Qf Document) Sistem Berjalan.

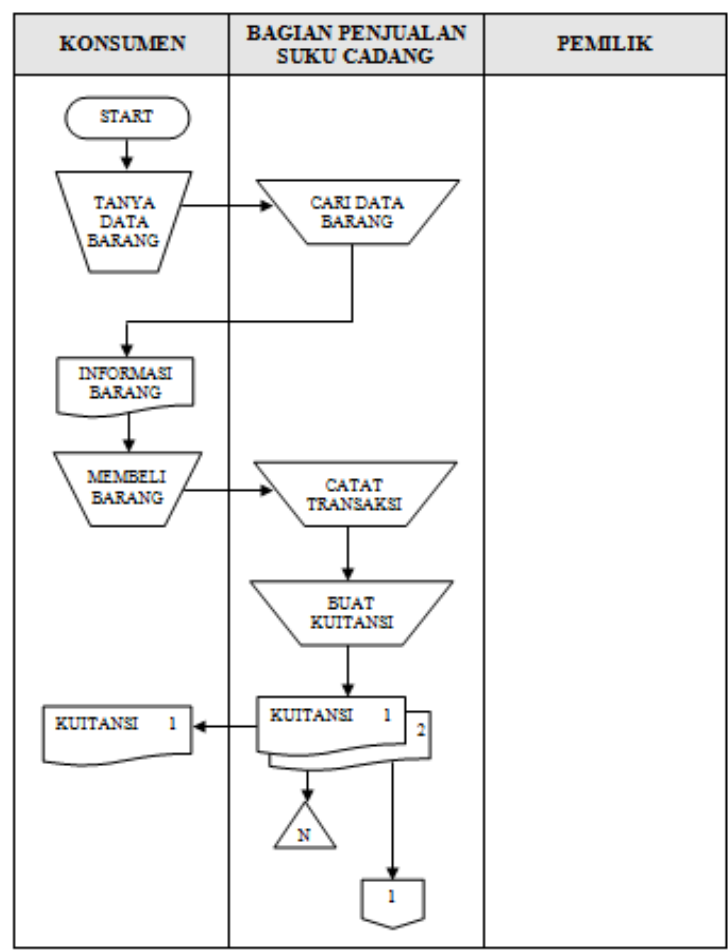

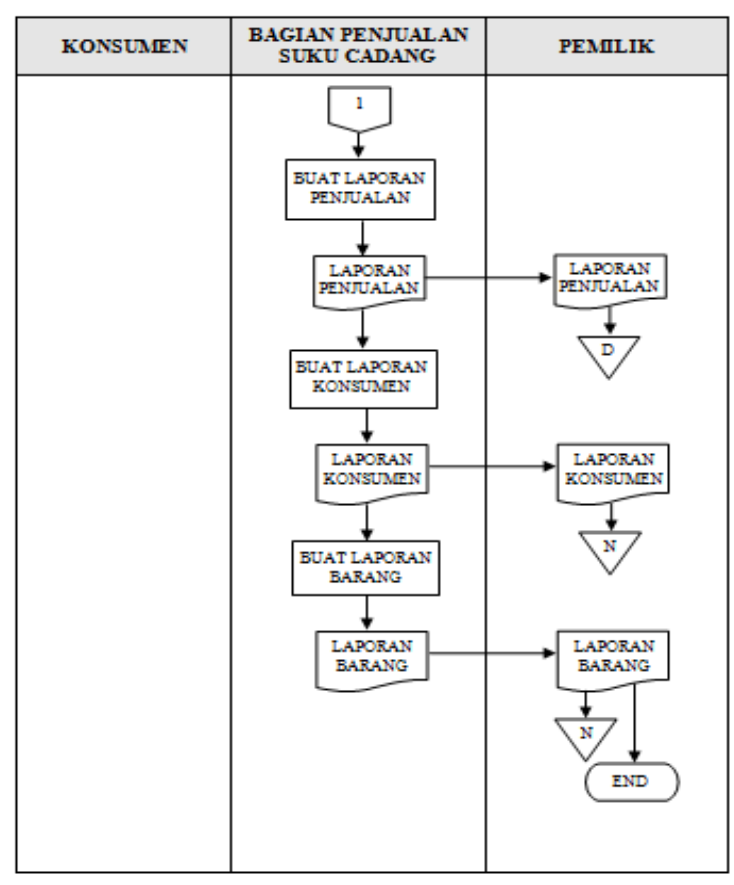

Gambar 31. Disgram Alir. Dokumen Sistem yang Berjalan.

\section{PEMBAHASAN}

\subsection{Perancangan output}

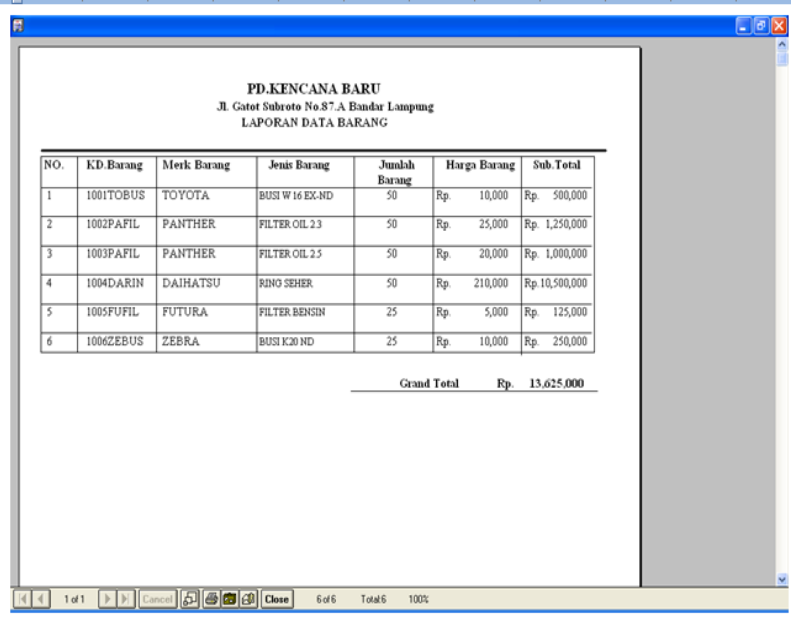

Gambar 4.1 output laporan data barang

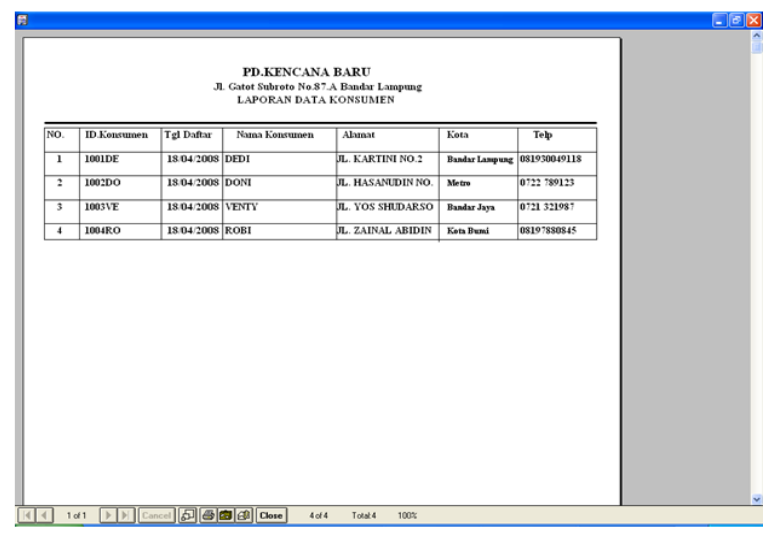


Gambar 4.2 Perancangan output laporan Data Barang

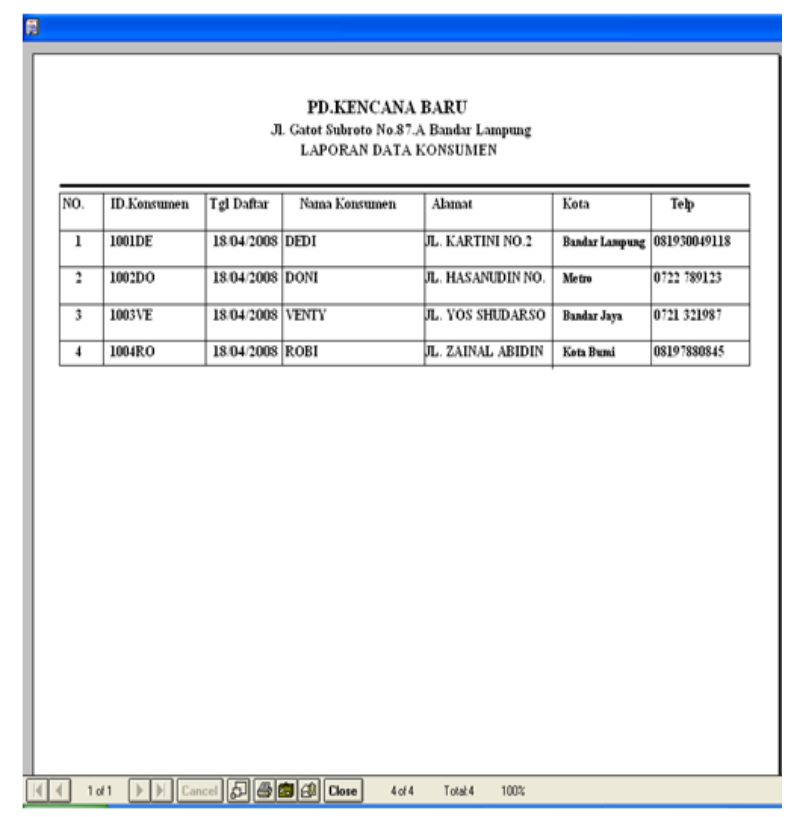

Gambar 4.3 Perancangan output laporan Data Konsumen



Gambar 4.4 Perancangan output laporan Data Penjualan

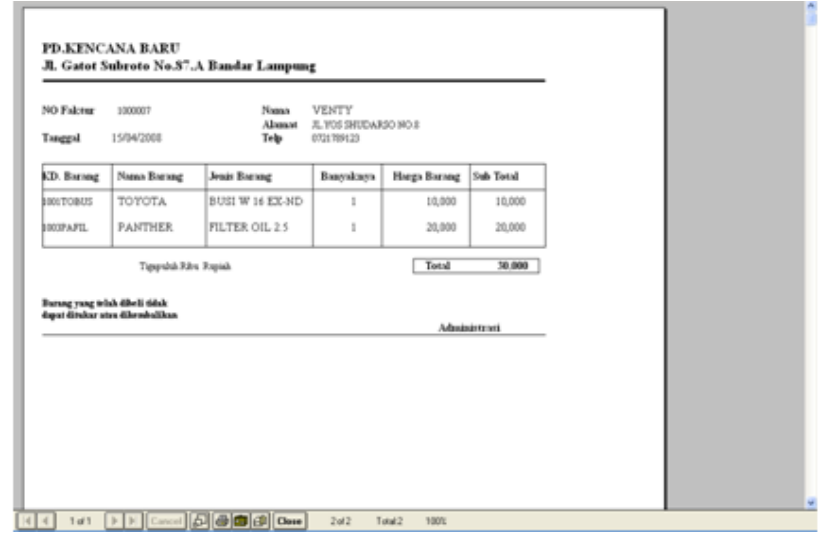

Gambar 4.5 Perancangan output laporan Nota Penjualan

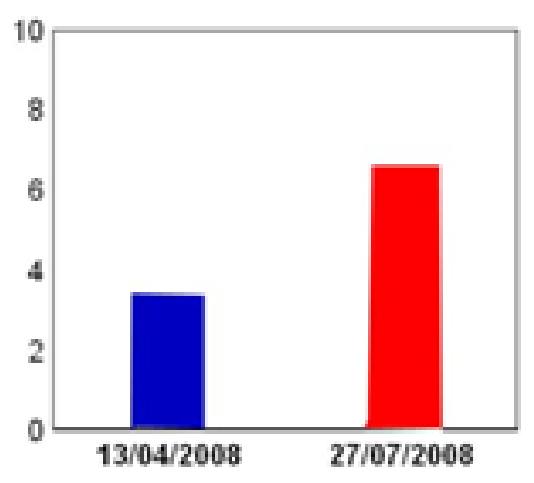

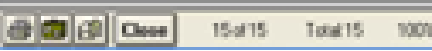

Gambar 4.6 Perancangan output laporan grafik penjualan

\section{KESIMPULAN DAN SARAN 5.1 KESIMPULAN}

Berdasarkan hasil pembahasan dari bab sebelumnya, maka peneliti dapat menyimpulkan, sebagai berikut :

1. PD. Kencana Baru dalam aktivitas kerja seharihari, seperti : proses transaksi penjualan serta pembuatan laporan masih dilakukan secara 
manual, sehingga data kemungkinan sering mengalami kehilangan.

2. PD.Kencana Baru masih menggunakan sistem informasi penjualan suku cadang secara manual sehingga hasil yang didapat kurang optimal, tidak efektif dan tidak efisien,

3. PD. Kencana Baru belum mengenal dan belum memiliki sistem komputerisasi yang mampu menunjang aktivitas kerja untuk mampu bersaing di pasaran,

Peralihan (switch over) perlu dilakukan oleh PD.Kencana Baru, dari sistem semi komputerisasi menjadi sistem terkomputerisasi

\subsection{SARAN}

Saran-saran dari peneliti untuk PD. Kencana

Baru yaitu :

1. Seiring dengan perkembangan zaman yang terus maju, yang memacu untuk lebih mampu bersaing di dunia bisnis, maka disarankan agar PD. Kencana Baru tidak lagi menggunakan sistem manual,

2. PD. Kencana Baru agar menggunakan sistem komputerisasi dalam melakukan segala aktivitas kerja, agar pekerjaan menjadi lebih cepat, efisien, dan efektif, serta hasil diperoleh lebih rapi dan tepat.

\section{DAFTAR PUSTAKA}

Dadan Umar Daihani. Komputerisasi Pengambilan Keputusan. Penerbit PT. Gramedia Jakarta. Jakarta: 2001.

Fathansyah. Basis Data. Penerbit Informatika Bandung. Bandung: 1999.

H. M. Jogiyanto. Analisis dan Desain Sistem Informasi. Penerbit Andi Yogyakarta. Yogyakarta: 1992.

Indra Yatini B. Pemrograman Terstruktur. Penerbit J\&J Learning Yogyakarta. Yogyakarta: 2001.

Raymond McLeod, Jr. Sistem Informasi Manajemen. Jilid Satu. Edisi Ketujuh. Penerbit PT. Prenhallindo. Jakarta: 1997. Wahana Komputer Semarang. Pemrograman Visual Basic 6.0. Penerbit Andi Yogyakarta. Semarang: 2000. Wiryanto Dewobroto. Aplikasi Sain dan Teknik dengan Visual Basic 6.0. Penerbit Elex Media Komputindo. Jakarta: 2003. 